\title{
XXX. On a remarkable property of arteries considered as a cause of animal heat
}

\section{J.M. Winn M.D.}

To cite this article: J.M. Winn M.D. (1839) XXX. On a remarkable property of arteries considered as a cause of animal heat, Philosophical Magazine Series 3, 14:88, 174-177, DOI: $10.1080 / 14786443908649702$

To link to this article: http://dx.doi.org/10.1080/14786443908649702

册 Published online: 01 Jun 2009.

Submit your article to this journal ¿

Џ Article views: 2

Q View related articles $\sqsubset$ 
which gives

$$
\alpha=-4 \pi^{2} \cdot \frac{\mathrm{B}_{2}}{\mathrm{~A}_{i}^{i}} \frac{x}{\lambda^{2}} .
$$

From this result we learn, 1 st, that since $\alpha$ is the same for all values of $t$, every molecule vibrates to and fro in a straight line; 2nd, that $\alpha$ varies as $\frac{x}{\lambda^{2}}$, that is, directly as the thickness of the crystal through which the ray has passed, and inversely as the square of the length of the wave.

These results are equivalent to the well-known experimental laws of Biot; hence we conclude that our formulæ (23.), (25.), (26.), (27.), represent correctly the motions which constitute a ray of light passing through the crystal in the direction of its axis.

On looking at the length of this paper I think it will be best to reserve the remainder of the investigation for another.

I am, Gentlemen, yours, \&c.

Littlemoor, Clitheroe, Jan. 9, 1839.

JoHN Tovey.

P.S. In the paper, vol. xii. p. 11, line 8, for $\phi(r)$ read $\phi(r) \Delta \eta$; ibid. line 9 , for $\phi(r)$ read $\phi(r) \Delta \zeta$; and p. 12, equations (7.) for $\rho_{11} a_{11}\left(n_{11} t-k x-b\right)$, read $\rho_{11} a_{11} \sin \left(n_{11} t\right.$ $-k x-b)$. The corrections of a few other errors in the same paper have been previously given.

XXX. On a remarkable Property of Arteries considered as a Cause of Animal Heat. By J. M. WINN, M.D.*

A BOUT three years since whilst making a few experiments $A$ with caoutchouc, I was forcibly struck with the property it possesses of evolving heat when suddenly stretched, and was led at the time to infer the probability of other bodies being similarly endowed. The elastic coat of arteries especially, from the mechanical resemblance it bears to caoutchouc, appeared to be one of the substances most likely to exhibit this calefactory principle; and in the event of this being the case it would not be unreasonable to conclude that the incessant contractions and dilatations of the arteries during life must prove an efficient source of animal heat.

During the past week I was induced to resume the subject afresh, and upon' making an experiment with part of the aorta of a bullock, I felt much gratification in being able to verify my previous conjecture. The experiment was per-

* Communicated by the Author. 
formed in the following manner. Having cut off a circular portion of the descending arch of the aorta, about an inch in length, I laid it open and carefully dissected out the elastic coat, and taking hold of it by each extremity, I pulled it to and fro with a continuous jerking motion (in imitation of the systole and diastole of the artery) for the space of about a minute, when placing it upon the bulb of a thermometer, I had the satisfaction to find that after it had remained two minutes the mercury had risen as many degrees. On removing the thermometer the heat immediately began to diminish. To be certain that the heat did not arise from any other source than the one in question, I took the precaution of covering my fingers with a double layer of flannel, to prevent the communication of heat from the body: I also covered my month with a handkerchief, to guard against the warm breath affecting the thermometer, whilst watching the progress of the experiment. I may likewise state that the experiment was performed in a room without a fire, the temperature of the air at the time being $55^{\circ}$. 'There were several difficulties to contend with during the investigation, and it was not until after repeated trials that the experiment succeeded to my satisfaction. The chief impediment I think must have been owing to the moisture of the artery, which by its evaporation must have had a constant tendency to carry off the heat. Having however performed the experiment twice consecutively in the same satisfactory manner, I think there can be but little doubt entertained as to its conclusiveness. My attention was often arrested, whilst conducting the experiments, by the striking mechanical analogies between caoutchouc and the elastic coat of arteries. Like the latter it could be elongated to twice its ordinary length, and, on withdrawing the tension, would return to its usual dimension with considerable force and a snapping noise. I was also surprised to find, on slightly drying it, that it would erase black-lead pencil marks from paper without leaving a stain. This latter circumstance is perhaps of trifling importance; it serves however to show that strong mechanical resemblance may exist between bodies widely differing in their chemical properties.

From the foregoing observations I think I am entitled to conclude that the whole of the heat developed in the animal œconomy can now be satisfactorily explained. Physiologists have often proved that the greater part of animal heat is occasioned by the chemical changes which take place in the lungs during respiration; there always remained however a portion which could not be referred to that source, but which can now I consider be fully accounted for by the mechanical 


\section{Dr. Winn on a remarkable Property of Arteries.}

action of the arteries. The precise quantity of heat given off during each beat of an artery, it would be exceedingly difficult, perhaps impossible, to discover ; but if we admit the development of only a very small quantity, it necessarily follows, from the circumstance of the action of the arteries being in incessant operation during life, that the heat must quickly accumulate to a great extent, and that the body unless cooled by the functions of the skin and lungs, would in a short space of time become preternaturally hot.

The following 'physiological and pathological facts appear to corroborate the view I have taken of the mechanical source of heat. 1st, The minute distribution of the arteries to every part of the system ensures a general and equal distribution of heat. 2ndly, The ossification of the arteries in old age, by diminishing their elasticity, is a probable cause of the diminution of animal heat at the close of life. 3rdly, The increased warmth of the body from exercise appears to be more readily explicable upon the principle of increased force in the arteries rather than that of increased vigour in the functions of the lungs, in as much as the immediate effect of exercise is evidently to embarrass the breathing, as shown by the hurried respiration. 4thly. In many diseases of the lungs where its functions are all at fault at a time when the arteries are beating with increased violence, the heat of the body is found to be above the usual standard. 5thly, Medicines which diminish the contractility and elasticity of the arteries almost invariably reduce the heat of the body. 6thly, The heat of local inflammations, in cases where the constitution does not sympathize to any extent, cannot be easily referred to any other source, as the arteries immediately in the neighbourhood of the affected part are throbbing with violence at a time when its capillaries (which are supposed to play so large a share in the chemical theory of heat) are generally considered to be entirely arrested. Many facts of a similar nature could be enumerated, but enough I think have been stated to establish the truth of the theory in question.

Of the nature of the mechanical force I have been investigating little can be said; it may possibly be a kind of intermolecular friction. It is clearly, however, of a different nature from ordinary friction, and which has also been considered a cause of animal heat; but I think erroneously so, for on examining the mechanism of the human body we find that everywhere the most efficient means of defence have been provided against its effects, as seen in the various synovial, mucous, and serous membranes, \&c. It is not the province, however, of the physiologist to speculate on the essential nature of me- 
chanical or vital forces. His legitimate object in the present state of the science would seem to be that of analysing the simplest operations in the human body:--to aim first at discovering the innumerable important processes that are carried on through the influence of physical agents, before he presumes to explain the higher and more mysterious principle of life: neither should he hastily call the vital power to his aid, to explain a phænomenon, such as heat, that is known to be common to every kind of matter, and which can be produced by a variety of physical forces totally independent of life.

Truro, Nov. 8, 1838.

XXXI. On the Passage of the Moon across the Pleiades in March, August, September, and November 1839. By the Rev. James Grooby, F.R.A.S.

[With a Chart : Plate V.]

To the Editors of the Philosophical Magazine and Journal.

\section{Gentiemen,}

THE annexed chart, showing the apparent path of the moon's centre over the Pleiades in the months of March, August, September, and November of the present year, might perhaps prove acceptable to some of your astronomical readers; but whether of sufficient importance to merit insertion in your next Number, I must leave to your determination. The occultation on the 19th of next month (March) will be particularly interesting; happening when the moon is only four days old, the whole of her disc will be visible; and as the immersions take place on the dark side, I have little doubt but that by excluding the enlightened part from the field of view, and using a telescope of considerable power, most, if not all, the telescopic stars which suffer occultation may be perceived, and their immersions observed. I should mention, that as astronomical telescopes, generally used in these observations, exhibit objects in an inverted order, the stars in the accompanying chart are inverted also, for the sake of more readily comparing them with the appearance in the telescope. In laying down the places of the stars, the right ascensions and declinations, as well as the numbers annexed to them, are taken from the catalogue of M. Jeaurat, as given by Mr. Baily in the Philosophical Magazine for September 1822, page 189, with the exception of No. 6, the declination of which as there given appears to be about $1^{\prime} 15^{\prime \prime}$ too small. Mr. Baily in projecting his chart has made the degrees of right ascension

Phil. Mag. S. 3. Vol. 14. No. 88. Mar. 1839. N 